\title{
Borderline or Schizophrenia? Cognitive Functioning as Differentiating Factor
}

\author{
Anna Mosiolek ${ }^{1^{*}}$ \\ ${ }^{1}$ Medical University of Warsaw Poland
}

Received: May 24, 2017; Accepted: June 22, 2017; Published: July 4, 2017

*Corresponding author: Anna Mosiolek, Medical University of Warsaw Psychiatric Clinic WNOZ 05-840 Pruszków, Poland. Email: manitka@tlen.pl

\begin{abstract}
Decompensations in BPD may appear similar to prodromal schizophrenic symptoms, giving clinicians a chance to use diagnostic tools that differentiate these phenomena basing on neuropsychological data. This study aims to investigate differences in cognitive functioning between inpatients with schizophrenia, in patients with BPD and healthy controls. 95 in patients with schizophrenia, 40 in patients with BPD and 68 healthy controls were examined with neuropsychological tests. The collected data were analyzed with focus on differences in cognitive functioning between groups. (1) Cognitive functioning can distinguish in patients with schizophrenia from inpatients with BPD. (2) Cognitive functioning is impaired more globally and deeply in patients with schizophrenia than in patients with BPD. (3) Subjects with BPD can present some selective impairment, but in some tasks they can also perform better than healthy controls. (4) Patients with schizophrenia presented significantly worse overall cognitive performance than patients with BPD and healthy controls.
\end{abstract}

\section{Introduction}

Borderline personality disorder is currently the most commonly diagnosed personality disorder $[57,9,60]$. It is estimated that the prevalence rate of BPD in the general population is $2 \%$ and about $25-40 \%$ among hospitalized patients $[9,60,19,36]$. Although first introduced in 1938 by the psychoanalyst Adolf Stern, the term borderline still causes a lot of controversy. Initially, the term borderline was used for the socalled borderline group of psychoneurosis and then for many years was considered a synonym of undifferentiated schizophrenia. This trend was followed by Rorschach, who understood the term borderline as the equivalent of hidden schizophrenia and Zilboorg, who used it for "ambulatory schizophrenia" [44]. A feature connecting all disorders included in the concept of borderline was the lack of clear psychotic symptoms, very bad social functioning and impaired interpersonal relationships. This term was used as a synonym for such diagnoses as mildly symptomatic schizophrenia, subclinical schizophrenia, prodromal schizophrenia, pseudoneurotic schizophrenia, latent schizophrenia, prepsychotic, atypical, non-psychotic and borderline schizophrenia. In the International Classification of Diseases - 10 (ICD - 10), the concepts of borderline and schizophrenia were separated, with a precise specification of the criteria for the recognition of the borderline type of emotionally unstable personality and the schizotypal disorders, which are the equivalent of borderline schizophrenia [25]. The feature most clearly clinically differentiating the two disorders is the affect: in the Schizotypal disorders - maladjusted and restricted (the person seems to be cold and distant) and in BPD (Borderline Personality Disorder) - shaky, capricious and unstable $[30,11,50]$. In the American classifications, the description of borderline personality appeared for the first time in the Diagnostic and Statistical Manual of Mental Disorders III (DSM- III, 1980) and the subsequent revisions introduced only minor corrections in the approach to the diagnostic criteria. The Diagnostic and Statistical Manual of Mental Disorders V (DSM-V, 2013), introduced in 2013, slightly differently defined the borderline spectrum - as in the European ICD-10 - calling it the borderline type. According to DSM-V the basic features of BPD are: unstable self-image, lack of purposes, disorders of interpersonal relationships, significant impairment in social and interpersonal functioning, severe mood swings, impulsiveness, risk-taking, suspicion and hostility $[1,2]$. Borderline patients ostensibly give the impression of wellfunctioning people and the full image and depth of their pathology are revealed only in the later stages of therapy [40]. The name itself arouses a lot of controversy and mental health experts generally agree that the term "borderline personality disorder" is misleading and may suggest an atypical course of the mental illness. The fact that some patients with severe BPD have psychotic episodes, meant that initially borderline was seen in the context of axis I "borderline subcategory" [3]. Studies show that acute psychotic symptoms with the clinical picture of schizophrenia or endogenous depression occur in up to $25-50 \%$ of people with BPD $[20,23,31,46]$. Although currently the borderline personality disorder is included in the spectrum of personality disorders in both the ICD-10 and the DSM - V, there are many tangent points between BPD and schizophrenia. In the pathogenesis of both BPD and schizophrenia, an important role is played by genetic, developmental and environmental factors. Studies of twins with borderline personality disorder suggest the impact of inheritance on the incidence of BPD. Individual studies have shown that genetics are responsible for the incidence of 35- 
$69 \%$ cases of BPD [56,55,12,59,15,27]. In the case of both schizophrenia and BPD, current research indicates that there is no one specific gene inducing the symptoms. Moreover, both groups of patients are linked by relatively poor social functioning, low percentage of people who are in steady relationships and a low percentage of people who are able to support themselves. It happens that people with BPD report productive symptoms, most commonly reporting a sense of threat, separateness and persecution. These symptoms can have an extremely turbulent and highly disorganizing character. Usually in the course of disorders we are dealing with short psychotic decompensations, however, in some patients we observe long-lasting psychotic depressions or symptoms that meet the criteria of schizophrenia. Therefore, in the case of productive symptoms similar to schizophrenia in the course of BPD, it would be useful to have additional tools that would help us decide whether it is a psychotic decompensation of borderline personality disorders or whether we are dealing with BPD and schizophrenia comorbidity. During the treatment of persons with BPD who experienced psychotic disorders, the diagnosticians frequently ask the question regarding the durability vs. the situational character of the psychotic process. It seems that after obtaining symptomatic improvement, testing of cognitive functions may support diagnostic hypotheses concerning the further planning of diagnosis and treatment. The occurrence of severe cognitive impairment in patients with BPD could therefore be a specific marker for the risk of developing schizophrenic psychosis. In the literature there are studies described, which confirm the occurrence of disorders of cognitive functions both in patients with BPD and patients with schizophrenia. In schizophrenia, they may precede the onset of the first episode even by 10 years, which is why some researchers believe that the treatment of schizophrenia in the category of a psychotic disorder suppresses the understanding of this disease [28]. Cognitive disorders are both a risk factor for schizophrenia and a prognostic-predictive factor [26,33]. In patients with schizophrenia, disorders of operational memory and executive functions are found as well as disorders in the selection and processing of information, attention and language functions $[16,39,18]$. The most commonly described cognitive dysfunctions occurring in BPD include abnormal patterns of cognitive processing of emotions, which is associated with individually inherited and shaped strategies and a biological predisposition to low stress tolerance. The biopsychosocial hypothesis of the etiopathogenesis of BPD assumes the incidence of axial disorders of cognitive functions as an effect of abnormalities in the neural network, especially in the prefrontal cortex. Clinicians dealing with issues of BPD, have proposed a model in which there is a relationship between the disorders in the basic neurocognitive processes and the symptoms and behaviors typical for BPD $[17,48]$. These dysfunctions would be responsible for the incidence of borderline personality features [38]. Low threshold for triggering aggression, irritability and impulsiveness which are characteristic for the borderline personality may be associated with the excessive reactivity of the amygdala, a decrease in the prefrontal role of inhibition and control, glutaminergic hyperactivity, resulting in an increased reactivity to emotional stimuli in the external environment and the occurrence of abnormal neuronal networks between the prefrontal cortex and the limbic system $[5,49,52]$. Neurobiological studies indicate that the incidence of borderline features is at least partly associated with changes in the systems of glutamatergic dopaminergic and serotonergic neuronal pathways $[13,27]$. At the same time, there is evidence that the pharmacotherapy acting on these neurotransmitters can be effective in the treatment of BPD and together with the psychotherapeutic interactions provides the foundation of an integrated approach to treatment. That is why neuroleptics are increasingly used in severe BPD and are applied in the majority of adult patients with this diagnosis [53,37,6,34]. The usefulness of this group of drugs is confirmed by meta-analysis of twentyseven clinical trials in which the effectiveness of antipsychotic drugs in the treatment of BPD was assessed [34]. The results of the studies show, that after the inclusion of pharmacotherapy, most patients achieve an improvement in the reduction of impulsiveness, tension, suspicion and hostility, mood swings, undertaken aggressive actions and suicidal attempts [53,34]. It should be noted, however, that there are currently no drugs approved by the U.S. Food and Drug Administration for the treatment of borderline personality disorder. Although people with borderline personality disorder tend to be very unstable emotionally, inconstant, full of anger or impulsive, they are still able to function well for long periods of time, especially with a clear external structure. The continuum of disorders may be closer to the norm or move in the direction of mental illness.

\section{Method}

iA total of 220 people were examined, out of which 100 people had been diagnosed with schizophrenia, 52 people - with borderline personality disorder and 68 people came from the healthy population. People from the clinical groups were examined in the general psychiatric departments in [blind review] in the course of standard psychological diagnosis. People from the control group were asked to participate in the study and gave their consent. In the clinical groups, depending on the characteristics of the disorders, the levels of their symptoms were measured. In the group of people with schizophrenia a measurement of the symptoms using the Positive and Negative Syndrome Scale (PANSS), a measurement of the mood using the Montgomery-Asberg Rating Scale (MADRS) and a measurement of the unwanted side effects of the pharmacological treatment using the UKU Side Effects Rating Scale were carried out [29,43,35]. Individuals with borderline personality disorder were classified into the group based on the Structured Clinical Interview for DSM-IV Axis II Personality (SCID-II) structured clinical interview and the measurement of the level of symptoms was performed using the Borderline Symptom List 23 (BSL-23) Borderline 
Symptom Checklist scale, which serves both for the assessment of the general level of borderline personality traits as well as the (auto)destructive behaviors occurring in the decompensation [7].

In order to investigate the characteristics of cognitive functioning in the individual groups, neuropsychological tests were performed in the examined patients in such a way, so that each group of cognitive functions was represented by one test method. Verbal-linguistic learning was examined using the Rey's Auditory Verbal Learning Test (RAVLT), visual memory and perceptual structuring using the Rey-Ostrrieth Complex Figure Test (ROCFT), phonemic verbal fluency according to the standard procedure (the letter $\mathrm{A}$ was selected) and the control and supervisory functions using the Trail Making Test (TMT) A and TMT B $[10,54,47]$. In the study of the verbal-linguistic learning function a stripped-down Polish version of the RAVLT was used. Essential demographic data was also collected. The examination procedure consisted in the examined person reading a series of 15 words (List A), from which the examined person was supposed to repeat as many words as possible. This procedure was repeated five times, so that the examined person had the opportunity to learn the examination material. Subsequently a different list (list B) was read once, with the command to repeat as many words as possible. Later, the examined person was asked to recall from memory the words from list A. After 30 minutes, the examiner asked the examined person to recreate without prompting the words from the A list. The number of individual words in the series $\mathrm{A} 1-\mathrm{A} 5$, in the list B, spontaneous recalling without postponement and after postponement were taken as the indicators of the performance of the test. In the ROCFT test the examined persons were supposed to copy a complex figure and then recreate it from memory after 3-5 minutes. The numbers of points awarded for the correctly reproduced elements of the figure were adopted as the performance indicator. The scoring assumed that if the element is properly placed and mapped, 2 points are awarded, for an incorrectly positioned element without distortions 1 point was awarded, for a properly placed distorted element - 1 point, a distorted, incorrectly placed but recognizable element was awarded with 0.5 points and for the lack of the element or it being unrecognizable - 0 points were awarded. In the TMT A and $\mathrm{B}$, the time of the correct performance of each part of the test was adopted as the measuring indicator. In the test of verbal fluency, the number of words given in 1 minute was adopted as the performance indicator.

Out of the observations obtained from the examined groups (100 individuals with schizophrenia, 68 healthy individuals and 52 patients with BPD), those which were suitable for further analysis were selected. The extreme observations were removed (results above or below 3 standard deviations) and the examined persons whose data had too many gaps were excluded. Ultimately the following sample groups were qualified for further analysis: 95 people with schizophrenia, 68 healthy subjects and 40 people with BPD. The number of people in the various analyzes may differ slightly from these values, due to single data gaps. Due to the unfulfilled requirements for parametric statistics, the $U$ Mann-Whitney test was used for all analyzes.

Analysis of demographic data which are potentially relevant for the interpretation of the results further indicates that there are no significant differences in terms of age between the examined sample groups (Tables 1,2). The groups of people with schizophrenia and people with BPD did not differ in terms of the number of years of formal education either.

\begin{tabular}{|c|c|c|c|}
\hline & $\begin{array}{c}\text { M } \\
\text { (Schizophrenia) }\end{array}$ & $\begin{array}{c}M \\
\text { (BPD) }\end{array}$ & M (Control group) \\
\hline Age: & 31.53 & 29.95 & 32.69 \\
\hline $\begin{array}{c}\text { Years of } \\
\text { education }\end{array}$ & 12.82 & 13.58 & 15.03 \\
\hline
\end{tabular}

Table 2 Tests of significance of the differences between the groups (age and years of education)

\begin{tabular}{|c|c|c|c|c|c|}
\hline & $\begin{array}{c}\text { U Mann-Whitney } \\
\text { Schizophrenia - BPD }\end{array}$ & Significance & $\begin{array}{c}\text { U Mann-Whitney } \\
\text { Schizophrenia - } \\
\text { Control group }\end{array}$ & $\begin{array}{c}\text { Significance } \\
\text { BPD - Control } \\
\text { group }\end{array}$ & $\begin{array}{c}\text { Significance } \\
\text { Age: }\end{array}$ \\
\hline $\begin{array}{c}\text { Years of } \\
\text { education }\end{array}$ & 1693.5 & 0.32 & 3070.5 & 0.591 & $0.000^{*}$ \\
\hline * significance $p<0,05$ & 1599.5 & 0.14 & 1978.5 & $0.08 *$ \\
\hline
\end{tabular}

The only significant difference between the examined groups turned out to be the difference in the number of years of education between the group of people with schizophrenia and the healthy group. The difference of the averages is 2.5 years.

The structure of sexes in the individual groups turned out to be quite diverse (Table 3). While in the control group the number of women and men was relatively balanced, in the group of patients with schizophrenia a slight numerical dominance of women was noted and in the group of patients with BPD there was a clear predominance of women. 
At the same time it is worth noting, that while the structure of sexes in the group with BPD relatively corresponded to the actual proportions, in the clinical group of people with schizophrenia, there is a slight shortage of observations coming from men (Table 3).

Table 3: The structure of sexes in the individual groups - the numbers

\begin{tabular}{|c|c|c|c|c|}
\hline & & \multicolumn{3}{|c|}{ Group } \\
\hline & & Schizophrenia & $\begin{array}{c}\text { Healthy } \\
\text { individuals }\end{array}$ & BPD \\
\hline \multirow[t]{2}{*}{ Sex } & Women & 54 & 33 & 37 \\
\hline & Men & 41 & 35 & 3 \\
\hline \multicolumn{2}{|c|}{ Overall } & 95 & 68 & 40 \\
\hline
\end{tabular}

In both examined clinical groups the majority of the examined people didn't remain in steady relationships. The fewest people staying in steady relationships were found in the group of people suffering from schizophrenia. In the control group most people remained in relationships (Table 4).

Table 4: The relationship status in the individual groups - the numbers

\begin{tabular}{|c|c|c|c|c|}
\multicolumn{2}{|c|}{ Schizophrenia } & \multicolumn{3}{c|}{ Group } \\
\cline { 2 - 5 } & $\begin{array}{c}\text { Healthy } \\
\text { individuals }\end{array}$ & BPD & \\
\hline \multirow{2}{*}{$\begin{array}{c}\text { Relationship } \\
\text { status }\end{array}$} & $\begin{array}{c}\text { In } \\
\text { relationship }\end{array}$ & 82 & 25 & 26 \\
\cline { 2 - 5 } & 13 & 43 & 14 \\
\hline \multicolumn{2}{|c|}{ Overall } & 95 & 68 & 40 \\
\hline
\end{tabular}

In both clinical groups, the vast majority of the examined people subsisted on social benefits or the help of relatives. In the control group, most of the examined people worked for a living (Table 5).

Table 5 :Livelihoods in the individual groups - the numbers

\begin{tabular}{|c|c|c|c|c|}
\hline & & \multicolumn{3}{|c|}{ Group } \\
\hline & Schizophrenia & $\begin{array}{c}\text { Healthy } \\
\text { individuals }\end{array}$ & BPD & \\
\hline \multirow{5}{*}{ Livelihood } & Work & 8 & 49 & 10 \\
\hline & Pension & 44 & 3 & 5 \\
\hline & $\begin{array}{c}\text { Permanent } \\
\text { benefits }\end{array}$ & 9 & 0 & 4 \\
\hline & Help & 32 & 16 & 20 \\
\hline & None & 1 & 0 & 1 \\
\hline \multicolumn{2}{|c|}{ Overall } & 94 & 68 & 40 \\
\hline
\end{tabular}

Most people with schizophrenia manifested average severity of positive and negative symptoms measured by the PANSS scale and a mildly depressed mood (MADRS). The severity of the side effects of drugs was low (UCU). The patients were treated with both atypical and classical neuroleptics in oral and depot form. All the dosages of the received medicines in patients with schizophrenia were converted for statistical purposes and accordingly to current norms to chlorpromazine equivalents. The average dosage of the used treatment converted to chlorpromazine equivalents was $66 \mathrm{mmg}$. The maximum dosage used was $1633 \mathrm{mg}$, whilst the minimal - $75 \mathrm{mg}$ converted to chlorpromazine. In nearly half of the cases examined combined therapy was used (more than one neuroleptic at a time). There was a dominance of atypical neuroleptics $-62 \%$ of the subjects received II generation drugs and almost $30 \%$ out of the $62 \%$ received olanzapine. The neuroleptics used predominatingly included: olanzapine, clozapine, risperidone and perphenazine.

\section{Results}

\section{Comparison of the results of the group of people with schizophrenia and the control group.}

The results of the $\mathrm{U}$ Mann-Whitney tests indicate the existence of significant differences between the group of individuals with schizophrenia and the control group in terms of the number of words memorized in the 15 words test. Healthy individuals were able to reproduce significantly more words in each of the possible test series, than those with schizophrenia. The significance statistics are presented in (Table 6).

Table 6: Average ranks and tests of the significance of differences between people with schizophrenia $(\mathrm{N}=95)$ and healthy individuals $(\mathrm{N}=67)$ - verballinguistic learning

\begin{tabular}{|c|c|c|c|c|}
\hline Variables & $\begin{array}{c}\text { Average rank } \\
\text { schizophrenia }\end{array}$ & $\begin{array}{c}\text { Average rank } \\
\text { healthy individuals }\end{array}$ & $\begin{array}{c}\text { U Mann- } \\
\text { Whitney }\end{array}$ & Significance \\
\hline RAVLT 1 & 61.87 & 107.84 & 1350.5 & $0.000^{*}$ \\
\hline RAVLT 2 & 59.78 & 112.3 & 1119 & $0.000^{*}$ \\
\hline RAVLT 3 & 58.75 & 113.75 & 1021.5 & $0.000^{*}$ \\
\hline RAVLT 4 & 59.11 & 113.25 & 1055 & $0.000^{*}$ \\
\hline RAVLT 5 & 59.51 & 112.69 & 1093 & $0.000^{*}$ \\
\hline B List & 58.05 & 114.75 & 954.500 & $0.000^{*}$ \\
\hline Recalling & 61.87 & 109.34 & 1317.5 & $0.000^{*}$ \\
\hline $\begin{array}{c}\text { After } \\
\text { postponement }\end{array}$ & 59.06 & 113.32 & 1050.500 & $0.000^{*}$ \\
\hline * significance p $<0,05$ & & & \\
\hline
\end{tabular}

Healthy individuals also obtained a significantly higher average number of points for copying and reproduction of the test material in the Rey Complex Figure Test. This means that the hospitalized persons with schizophrenia memorize fewer visual elements and poorly organize and structure the visual material, 
which has a significant impact on the ability to memorize and recreate it (Table 7).

Table 7: Average ranks and tests of the significance of differences between people with schizophrenia $(\mathrm{N}=95)$ and healthy individuals $(\mathrm{N}=68)$ - visual function

\begin{tabular}{|c|c|c|c|c|}
\hline & $\begin{array}{c}\text { Average rank } \\
\text { schizophrenia }\end{array}$ & $\begin{array}{c}\text { Average } \\
\text { rank healthy } \\
\text { individuals }\end{array}$ & $\begin{array}{c}\text { U Mann- } \\
\text { Whitney }\end{array}$ & Significance \\
\hline ROCFT copy & 51.44 & 124.69 & 327 & $0.000^{*}$ \\
\hline $\begin{array}{c}\text { ROCFT } \\
\text { reproduction }\end{array}$ & 49.55 & 127.33 & 147.5 & $0.000^{*}$ \\
\hline * significance $\mathrm{p}<0,05$ & & & \\
\hline
\end{tabular}

Patients with schizophrenia during hospitalization exhibit a significantly lower ability of phonemic updating of words than healthy individuals. The examined patients from the clinical group were able to generate significantly fewer words starting with the letter A than the examined persons from the control group (Table 8).

Table 8: Average ranks and tests of the significance of differences between people with schizophrenia $(\mathrm{N}=95)$ and healthy individuals $(\mathrm{N}$ =67) - verbal fluency.

\begin{tabular}{|c|c|c|c|c|}
\hline Variables & $\begin{array}{l}\text { Average rank } \\
\text { schizophrenia }\end{array}$ & $\begin{array}{c}\text { Average } \\
\text { rank healthy } \\
\text { individuals }\end{array}$ & $\begin{array}{l}\text { U Mann- } \\
\text { Whitney }\end{array}$ & Significance \\
\hline $\begin{array}{l}\text { Verbal } \\
\text { fluency }\end{array}$ & 61.51 & 109.84 & 1283.5 & $0.000^{*}$ \\
\hline
\end{tabular}

Likewise the times of the proper performance of the Trail Making Test TMT A and TMT B in people with schizophrenia turned out to be significantly higher than in the people from the control group, both in task A and in task B. Average ranks in people with schizophrenia twice exceeded the average ranks obtained in the group of healthy individuals (Table 9).

Table 9 :Average ranks and tests of the significance of differences between people with schizophrenia $(N=95)$ and healthy individuals $(N=67)$ control and supervision function

\begin{tabular}{|c|c|c|c|c|}
\hline Variables & $\begin{array}{c}\text { Average rank } \\
\text { schizophrenia }\end{array}$ & $\begin{array}{c}\text { Average } \\
\text { rank healthy } \\
\text { individuals }\end{array}$ & $\begin{array}{c}\text { U Mann- } \\
\text { Whitney }\end{array}$ & Significance \\
\hline TMT A & 106.54 & 47.72 & 899 & $0.000^{*}$ \\
\hline TMT B & 107.18 & 46.82 & 837.5 & $0.000^{*}$ \\
\hline
\end{tabular}

Therefore people with schizophrenia had significantly weaker results with regard to each of the measured functions, that is, verbal-linguistic learning, visual memory and perceptual structuring, verbal fluency as well as control and supervisory functions

\section{Comparison of the results of the group of people with BPD and the control group}

The comparative analysis of the results of people with BPD and the control group indicates the existence of numerous differences in the cognitive functioning between these groups. The first of these is a significantly higher efficiency of verbal-linguistic learning in the people with BPD, manifested in higher number of words recovered from memory in the individual attempts during the Rey 15 words test. The examined persons from the group with BPD achieved higher scores in all possible test attempts (Table $10)$.

Table 10: Average ranks and tests of the significance of differences between people with BPD $(\mathrm{N}=38)$ and healthy individuals $(\mathrm{N}=67)-$ verbal-linguistic learning

\begin{tabular}{|c|c|c|c|c|}
\hline Variables & $\begin{array}{c}\text { Average } \\
\text { rank BPD }\end{array}$ & $\begin{array}{c}\text { Average } \\
\text { rank healthy } \\
\text { individuals }\end{array}$ & $\begin{array}{c}\text { U Mann- } \\
\text { Whitney }\end{array}$ & Significance \\
\hline RAVLT 1 & 69.36 & 43.72 & 651.5 & $0.000^{*}$ \\
\hline RAVLT 2 & 67.03 & 45.04 & 740 & $0.000^{*}$ \\
\hline RAVLT 3 & 65.61 & 45.85 & 794 & $0.001^{*}$ \\
\hline RAVLT 4 & 65.99 & 45.63 & 779.5 & $0.001^{*}$ \\
\hline RAVLT 5 & 64.36 & 46.56 & 841.5 & $0.004^{*}$ \\
\hline B List & 62.14 & 47.81 & 925.5 & $0.019^{*}$ \\
\hline Recalling & 65.67 & 45.81 & 791.5 & $0.001^{*}$ \\
\hline $\begin{array}{c}\text { After } \\
\text { postponement }\end{array}$ & 62.7 & 46.87 & 862 & $0.010^{*}$ \\
\hline * & & & \\
\hline
\end{tabular}

* significance $\mathrm{p}<0,05$

In terms of structuring, memorization and reproduction of visual material significant differences were found between the two groups. Healthy individuals have obtained significantly better results than those with BPD in the reproduction part, receiving more points for the number of reconstructed elements of the test figures (Table 11). However, this regularity did not apply during the subtest associated with copying the visual material.

Table 11: Average ranks and tests of the significance of differences between people with BPD $(N=38)$ and healthy individuals $(N=68)$ visual functions

\begin{tabular}{|c|c|c|c|c|}
\hline Variables & $\begin{array}{c}\text { Average } \\
\text { rank BPD }\end{array}$ & $\begin{array}{c}\text { Average } \\
\text { rank healthy } \\
\text { individuals }\end{array}$ & $\begin{array}{c}\text { U Mann- } \\
\text { Whitney }\end{array}$ & Significance \\
\hline ROCFT copy & 47.38 & 57.79 & 1068 & 0.084 \\
\hline $\begin{array}{c}\text { ROCFT } \\
\text { reproduction }\end{array}$ & 22.46 & 69.62 & 128 & $0.000^{*}$ \\
\hline * significance $p<0,05$ & & & \\
\hline
\end{tabular}

In terms of phonemic fluency, individuals from the control group received on average significantly higher scores than those with BPD, updating a greater average number of words beginning with the letter A (Table 12). 
Table 12: Average ranks and tests of the significance of differences between people with BPD $(\mathrm{N}=38)$ and healthy individuals $(\mathrm{N}=67)$ verbal fluency

\begin{tabular}{|c|c|c|c|c|}
\hline Variables & $\begin{array}{c}\text { Average } \\
\text { rank BPD }\end{array}$ & $\begin{array}{c}\text { Average } \\
\text { rank healthy } \\
\text { individuals }\end{array}$ & $\begin{array}{c}\text { U Mann- } \\
\text { Whitney }\end{array}$ & Significance \\
\hline $\begin{array}{c}\text { Verbal } \\
\text { fluency }\end{array}$ & 34.08 & 61.63 & 561 & $0.000^{*}$ \\
\hline
\end{tabular}

* significance $\mathrm{p}<0,05$

Healthy individuals performed the TMT A test in a significantly shorter time than people with BPD. In terms of results in the TMT B test, there were no significant differences between the groups (Table 13).

Table 13: Average ranks and tests of the significance of differences between people with BPD $(\mathrm{N}=39)$ and healthy individuals $(\mathrm{N}=67)$ control and supervision functions

\begin{tabular}{|c|c|c|c|c|}
\hline Variables & $\begin{array}{c}\text { Average rank } \\
\text { BPD }\end{array}$ & $\begin{array}{c}\text { Average } \\
\text { rank healthy } \\
\text { individuals }\end{array}$ & $\begin{array}{c}\text { U Mann- } \\
\text { Whitney }\end{array}$ & Significance \\
\hline TMT A & 62.81 & 48.95 & 982.5 & $0.026^{*}$ \\
\hline TMT B & 59.92 & 50.60 & 1095 & 0.135 \\
\hline
\end{tabular}

The general results of the comparisons indicate the existence of both favorable as well as unfavorable features of cognitive functioning for people with BPD, differentiating this group from healthy individuals. The favorable features relate to the verbal-linguistic learning, the unfavorable - to attention functions, verbal fluency and recovering visual material from memory. It is possible that emotional and motivational factors could have had an impact on the results in patients with BPD.

\section{Comparison of the results of the group of people with $B P D$ and the group of people with schizophrenia}

In terms of verbal-linguistic learning the group of people with BPD fared significantly better than the group of people with schizophrenia. The results obtained in the individual attempts by persons with BPD are significantly higher (number of recalled words) than in patients suffering from schizophrenia. The results are presented in (Table 14).

People with BPD also copy the stimulus figure in the Rey Complex Figure Test significantly more efficiently. In terms of quantity and quality of the reproduced elements in the Reproduction, these groups did not differ significantly from each other (Table 15).

Also in relation to verbal fluency the groups of people with BPD and schizophrenia have not demonstrated significant differences. There were no systematic differences in the number of words updated by the people from those groups (Table 16).

On the other hand, in terms of the time of performance of the attempts in the TMT A and TMT B test, there are significant differences between the groups. People with BPD obtained on average significantly shorter test performance times (Table 17).
Table 14: Average ranks and tests of the significance of differences between people with BPD $(\mathrm{N}=39)$ and people with schizophrenia $(\mathrm{N}=$ 95) - verbal-linguistic learning

\begin{tabular}{|c|c|c|c|c|}
\hline Variables & $\begin{array}{c}\text { Average rank } \\
\text { BPD }\end{array}$ & $\begin{array}{c}\text { Average rank } \\
\text { schizophrenia }\end{array}$ & $\begin{array}{c}\text { U Mann- } \\
\text { Whitney }\end{array}$ & Significance \\
\hline RAVLT 1 & 104.49 & 51.14 & 342.5 & $0.000^{*}$ \\
\hline RAVLT 2 & 104.36 & 52.06 & 385.5 & $0.000^{*}$ \\
\hline RAVLT 3 & 105.09 & 51.76 & 357.5 & $0.000^{*}$ \\
\hline RAVLT 4 & 105.57 & 51.57 & 339.5 & $0.000^{*}$ \\
\hline RAVLT 5 & 105.01 & 51.79 & 360.5 & $0.000^{*}$ \\
\hline B List & 104.29 & 52.08 & 388 & $0.000^{*}$ \\
\hline Recalling & 104.64 & 51.94 & 374.5 & $0.000^{*}$ \\
\hline $\begin{array}{c}\text { After } \\
\text { postponement }\end{array}$ & 102.01 & 52.67 & 443.5 & $0.000^{*}$ \\
\hline * significance p $<0,05$ & & & \\
\hline
\end{tabular}

Table 15: Average ranks and tests of the significance of differences between people with BPD $(\mathrm{N}=39)$ and people with schizophrenia $(\mathrm{N}=$ 95) - visual functions

\begin{tabular}{|c|c|c|c|c|}
\hline Variables & $\begin{array}{c}\text { Average } \\
\text { rank BPD }\end{array}$ & $\begin{array}{c}\text { Average rank } \\
\text { schizophrenia }\end{array}$ & $\begin{array}{c}\text { U Mann- } \\
\text { Whitney }\end{array}$ & Significance \\
\hline ROCFT copy & 102.83 & 52.99 & 474.5 & $0.000^{*}$ \\
\hline $\begin{array}{c}\text { ROCFT } \\
\text { reproduction }\end{array}$ & 72.18 & 64.29 & 1547.5 & 0.29 \\
\hline * significance $\mathrm{p}<0,05$ & & & \\
\hline
\end{tabular}

Table 16: Average ranks and tests of the significance of differences between people with BPD $(\mathrm{N}=39)$ and people with schizophrenia $(\mathrm{N}$ =95) - verbal fluency

\begin{tabular}{|c|c|c|c|c|}
\hline Variables & $\begin{array}{c}\text { Average } \\
\text { rank BPD }\end{array}$ & $\begin{array}{c}\text { Average rank } \\
\text { schizophrenia }\end{array}$ & $\begin{array}{c}\text { U Mann- } \\
\text { Whitney }\end{array}$ & Significance \\
\hline $\begin{array}{c}\text { Verbal } \\
\text { fluency }\end{array}$ & 73.46 & 63.17 & 1441.500 & 0.17 \\
\hline
\end{tabular}

Table 17: Average ranks and tests of the significance of differences between people with BPD $(\mathrm{N}=39)$ and people with schizophrenia $(\mathrm{N}=$ 95) - control and supervision functions

\begin{tabular}{|c|c|c|c|c|}
\hline Variables & $\begin{array}{c}\text { Average } \\
\text { rank BPD }\end{array}$ & $\begin{array}{c}\text { Average rank } \\
\text { schizophrenia }\end{array}$ & $\begin{array}{c}\text { U Mann- } \\
\text { Whitney }\end{array}$ & Significance \\
\hline TMT A & 39.87 & 78.84 & 775 & $0.000^{*}$ \\
\hline TMT B & 38.85 & 79.26 & 735 & $0.000^{*}$ \\
\hline
\end{tabular}

* significance $\mathrm{p}<0,05$

The factors which differentiate the clinical groups are mainly the functions of control and supervision and the verballinguistic learning processes. 


\section{Discussion}

The results of the comparisons in the individual sample groups indicate the important role of cognitive functions in the differentiation of the clinical patients with BPD from the patients with schizophrenic psychoses. Learning processes in people with BPD seem to function even better than in healthy individuals, while the cognitive deficits in schizophrenic patients seem to impair the verbal learning processes. Similarly, in terms of the control and supervisory processes: it seems that even though people with BPD have attention difficulties, their attention switching processes do not appear to be permanently impaired and in this respect they exhibit more similarities to healthy individuals. In neuropsychological studies it should be expected, that in patients with schizophrenia decreased results in the full spectrum of cognitive functions may be obtained more frequently and in patients with BPD single decreased results, especially in terms of verbal fluency and recalling visual material from memory may be obtained more frequently. We can also speculate about the impact of emotional and motivational factors on the results within these two factors.

These results seem to confirm the earlier studies and observations concerning the cognitive dysfunctions in BPD. Many neuropsychological studies confirm the existence of differences in cognitive functioning between people with BPD and healthy people $[14,4,8,48,42]$. In $\mathrm{BPD}$, as shown by studies conducted thus far, the impairment of the complex cognitive processes is primarily connected with the dysfunctions of the frontal lobe circuits and affects areas such as interests, cognitive flexibility, learning and memory, planning, processing speed, visuospatial skills [51]. Deficits in terms of visuospatial functions in patients with BPD were observed in a group of 25 outpatients with a diagnosis of borderline personality disorder according to the DSM-III criteria [24]. BPD patients performed worse in visuospatial skills tests and tests associated with information processing, while there were no significant differences in tests assessing attention, verbal memory and alternate learning $[14,24,45]$. The memory disorders occurring in BPD may be related to emotional factors and symptoms of interpersonal hostility [41]. In our study, even though we observed the occurrence of deficits in attention in patients with BPD, the attention processes did not appear to be permanently damaged. The occurrence of permanent deficits in the scope of attention (attention, awareness and acceptance of the present moment) may be a predictor of the increase of pathology in BPD [58]. In the literature there is divergent data reported concerning the occurrence of executive dysfunctions in patients with BPD. The Wupperman study conducted on 29 patients with BPD confirms the existence of disorders of executive functions in respect to planning [58]. Similar results were obtained in the Bazanis study conducted on a group of 42 people diagnosed with BPD, where the BPD patients exhibited a delay in decision making and planning disorders [4]. These observations were confirmed by a study 27 patient with BPD, who generalized deficits in executive functions - planning, attention focus and working memory have been demonstrated [21]. A meta-analysis of 10 studies comparing the cognitive functioning of healthy individuals and people with BPD in terms of learning, memory, planning, visuospatial functions, attention, processing and cognitive flexibility has confirmed that people diagnosed with BPD perform cognitive tasks worse than the control group in all tested domains [48]. The worst results were obtained by patients with BPD in the area of planning of activities [14]. Despite the abundance of evidence supporting neurocognitive deficits in BPD, some studies do not confirm the occurrence of significant differences between people with BPD and healthy individuals from the control group $[22,32]$. Research involving neuropsychological diagnostics in combination with neuroimaging methods may produce a more comprehensive understanding of the spatial nature of the brain pathology in BPD. It should be emphasized that the cognitive dysfunctions in the course of BPD may play a role in the treatment process, affecting, among others, the ability of focusing attention, learning, planning and communication. Cognitive disorders could therefore become a specific predictor of the course of BPD and a routine assessment of the cognitive functions could help in determining the appropriate treatment and could have prognostic significance. Particular attention should be paid to issues such as: verbal-linguistic learning, control and supervisory functions and selectivity versus globality of the deficits.

The research shown in the present article is not flawless. Its first weakness is the heterogeneity in terms of sex in the BPD subjects. This is because BPD is rarely diagnosed in men. This fact together with the skewness in distribution of different variables makes the sex variable difficult to control in statistics, and this particular factor is significant in cognitive functioning. Furthermore, it is impossible to determine the value of variables associated with the time that elapsed from the onset of the disorder as well as the duration of treatment in BPD patients. It is difficult to mark the onset, as far as personality disorders are concerned, as well as the length of therapy, since those patients had undergone several treatments, including non-specific ones, and at different times. This problem makes it difficult to establish to what extent both clinical groups can be compared.

In summary, in neuropsychological research in patients with BPD, the deficits are selective and specific and relate to recalling visual material from memory, attention functions and verbal fluency, whereas in schizophrenia the decreased results relate to the full spectrum of the cognitive functions. The factors which differentiate the clinical groups are mainly the functions of control and supervision and the verbal-linguistic learning processes.

\section{References}

1. American Psychiatric Association. Diagnostic and statistical manual of mental disorders. 3rd Ed; Washington, DC: APA. 1980.

2. American Psychiatric Association. Personality disorders. In: Diagnostic and Statistical Manual of Mental Disorders DSM-5. 5th ed. Arlington. American Psychiatric Association. 2013.

3. Andrulonis PA, Glueck BC, Stroebel CF, Vogel NG. Borderline personal- 
ity subcategories. J Nerv Ment Dis. 1982;170(11):670-679.

4. Bazanis E, Rogers RD, Dowson JH, Taylor P, Meux C, Staley C. Neurocognitive deficits in decision-making and planning of patients with DSMIII-R borderline personality disorder. Psychol Med. 2002;32(8):13951405.

5. Beblo T, Saavedra AS, Mensebach C, Lange W, Markowitsch HJ, Rau $\mathrm{H}$, et al. Deficits in visual functions and neuropsychological inconsistency in Borderline Personality Disorder. Psychiatry Res. 2006;145(23):127-135. doi: 10.1016/j.psychres.2006.01.017

6. Binks CA, Fenton M, McCarthy L, Lee T, Adams CE, Duggan C. Pharmacological interventions for people with borderline personality disorder. Cochrane Database Syst Rev. 2006;(1):CD005653. doi: 10.1002/14651858.CD005653

7. Bohus M, Kleindienst N, Limberger MF, Stieglitz RD, Domsalla M, Chapman AL, et al. The short version of the Borderline Symptom List (BSL23): development and initial data on psychometric properties. Psychopathology. 2009;42(1):32-39. doi: 10.1159/000173701

8. Bozikas VP, Kosmidis MH, Anezoulaki D, Giannakou M, Karavatos A. Relationship of affect recognition with psychopathology and cognitive performance in schizophrenia. J Int Neuropsychol Soc. 2004;10(4):549-558. doi: 10.1017/S1355617704104074

9. Castaneda R, Franco H. Sex and ethnic distribution of borderline personality disorder in an inpatient sample. Am J Psychiatry. 1985;142(10):1202-1203. doi: 10.1176/ajp.142.10.1202

10.Choynowski M, Kostro B. Podręcznik do Testu 15 Słów Rey`a. In: Choynowski M. (Ed.).Testy psychologiczne. Warszawa: PWN. 1997;102-169.

11. Coifman KG, Berenson KR, Rafaeli E, Downey G. From negative to positive and back again: polarized affective and relational experience in borderline personality disorder. J Abnorm Psychol. 2012;121(3):668679. doi: $10.1037 / \mathrm{a} 0028502$

12. Coolidge FL, Thede LL, Jang KL. Heritability of personality disorders in childhood: a preliminary investigation. J Pers Disord. 2001;15(1):3340.

13.Dell'Osso B1, Berlin HA, Serati M, Altamura AC. Neuropsychobiological aspects, comorbidity patterns and dimensional models in borderline personality disorder. Neuropsychobiology. 2010;61(4):169-179. doi: 10.1159/000297734

14. Dinn WM, Harris CL, Aycicegi A, Greene PB, Kirkley SM, Reilly C. Neurocognitive function in borderline personality disorder. Prog Neuropsychopharmacol Biol Psychiatry. 2004;28(2):329-341. doi: 10.1016/j. pnpbp.2003.10.012

15. Distel MA, Trull TJ, Derom CA, Thiery EW, Grimmer MA, Martin NG, et al. Heritability of borderline personality disorder features is similar across three countries. Psychol Med. 2008;38(9):1219-1229. doi: 10.1017/S0033291707002024

16. Elvevåg B, Goldberg TE. Cognitive impairment in schizophrenia is the core of the disorder. Crit Rev Neurobiol. 2000;14(1):1-21.

17. Fertuck EA, Lenzenweger MF, Clarkin JF, Hoermann S, Stanley B. Executive neurocognition, memory systems, and borderline personality disorder. Clin Psychol Rev. 2006;26(3):346-375. doi: 10.1016/j. cpr.2005.05.008

18. Gold JM, Carpenter C, Randolph C, Goldberg TE, Weinberger DR. Auditory working memory and Wisconsin Card Sorting Test performance in schizophrenia. Arch Gen Psychiatry. 1997;54(2):159-165.

19. Gunderson JG. Borderline personality disorder: ontogeny of a diagnosis. The American Journal of Psychiatry. 2009;166(5):530-539.

20. Gunderson JG, Singer MT. Defining borderline patients: an overview. Am J Psychiatry. 1975;132(1):1-10. doi: 10.1176/ajp.132.1.1

21. Gvirts HZ, Harari H, Braw Y, Shefet D, Shamay-Tsoory SG, Levkovitz Y. Executive functioning among patients with borderline personality disorder (BPD) and their relatives. J Affect Disord. 2012;143(1-3):261264. doi: 10.1016/j.jad.2012.05.007

22. Agrawal HR, Gunderson J, Holmes BM, Lyons-Ruth K. Attachment studies with borderline patients: a review. Harv Rev Psychiatry. 2004;12(2):94-104. doi: 10.1080/10673220490447218

23. Hoch Ph, Cattell Jp, Strahl Mo, Pennes Hh. The course and outcome of pseudoneurotic schizophrenia. Am J Psychiatry. 1962;119:106-115. doi: 10.1176/ajp.119.2.106

24. Hoffman P, Ruff RM. Neuropsychological Dysfunction in Borderline Personality Disorder. Journal of Personality Disorders. 1993;7(4):275284. doi: $10.1521 /$ pedi.1993.7.4.275

25. ICD-10. International Classification of Diseases 10th Revision. (2010). World Health Organization. 2014.

26. Joyce EM. Cognitive function in schizophrenia: insights from intelligence research. British Journal of Psychiatry. 2013;203(3);161-162. doi: 10.1192/bjp.bp.112.109553

27. Joyce PR, Stephenson J, Kennedy M, Mulder RT, McHugh PC. The presence of both serotonin 1A receptor (HTR1A) and dopamine transporter (DAT1) gene variants increase the risk of borderline personality disorder. Front Genet. 2014;4:313. doi: 10.3389/fgene.2013.00313

28. Kahn RS, Keefe RS. Schizophrenia is a cognitive illness: time for a change in focus. JAMA Psychiatry. 2013;70(10):1107-1112. doi: 10.1001/jamapsychiatry.2013.155

29. Kay SR, Fiszbein A, Opler LA. The positive and negative syndrome scale (PANSS) for schizophrenia. Schizophr Bull. 1987;13(2):261-276.

30. Kernberg OF, Yeomans FE. Borderline personality disorder, bipolar disorder, depression, attention deficit/hyperactivity disorder, and narcissistic personality disorder: Practical differential diagnosis. Bull Menninger Clin. 2013;77(1):1-22. doi: 10.1521/bumc.2013.77.1.1

31. Kernberg 0 . The treatment of patients with borderline personality organization. Int J Psychoanal. 1968;49(4):600-619.

32. Kunert HJ, Druecke HW, Sass H, Herpertz SC. Frontal lobe dysfunctions in borderline personality disorder? Neuropsychological findings. J Pers Disord. 2003;17(6):497-509.

33. Kuperberg G, Heckers S. Schizophrenia and cognitive function. Current Opinion in Neurobiology. 2000;10(2);205-210. doi:- 10.1016/S09594388(00)00068-4

34. Lieb K, Völlm B, Rücker G, Timmer A, Stoffers JM. Pharmacotherapy for borderline personality disorder: Cochrane systematic review of randomised trials. Br J Psychiatry. 2010;196(1):4-12. doi: 10.1192/bjp. bp.108.062984

35. Lingjaerde O, Ahlfors UG, Bech P, Dencker SJ, Elgen K. The UKU side effect rating scale. A new comprehensive rating scale for psychotropic drugs and a cross-sectional study of side effects in neuroleptic-treated patients. Acta Psychiatr Scand Suppl. 1987;334:1-100.

36. Marinangeli MG, Butti G, Scinto A, Di Cicco L, Kalyvoka A, Petruzzi C, et al. Personality disorders prevalence study among inpatients with 
mood disorders, psychoactive use disorders and anxiety disorders. Epidemiol Psichiatr Soc. 2000;9(1):36-44.

37. Markovitz P. Pharmacotherapy of impulsivity, aggression, and related disorders, in Impulsivity and Aggression. New York: E. Hollander, DJ Stein, John Wiley \& Sons. 1995:263-287.

38. Meares R, Stevenson J, Gordon E. A Jacksonian and biopsychosocial hypothesis concerning borderline and related phenomena. Australian \& New Zealand Journal of Psychiatry. 1999;33(6):831-840.

39. Mehta UM, Thirthalli J, Naveen Kumar C, Keshav Kumar J, Keshavan MS, Gangadhar BN. Schizophrenia patients experience substantial social cognition deficits across multiple domains in remission. Asian Journal of Psychiatry. 2013;6(4);324-329. doi: 10.1016/j.ajp.2013.02.001

40. Millon T, Davis RD. Borderline personality disorders: The unstable pattern. In Disorders of personality DSM-IV and beyond (2nd ed.). New York: John Wiley \& Sons, Inc. 1996:645-690.

41. Minzenberg MJ, Fisher-Irving M, Poole JH, Vinogradov S. Reduced SelfReferential Source Memory Performance is Associated with Interpersonal Dysfunction in Borderline Personality Disorder. J Pers Disord. 2006;20(1):42-54. doi: 10.1521/pedi.2006.20.1.42

42.Monarch ES, Saykin AJ, Flashman LA. Neuropsychological impairment in borderline personality disorder. Psychiatr Clin North Am. 2004;27(1):67-82. doi: 10.1016/S0193-953X(03)00109-6

43. Montgomery SA, Asberg M. A new depression scale designed to be sensitive to change. Br J Psychiatry. 1979;134:382-389.

44. Mosiołek A, Koweszko T. Leczenie pogranicznych zaburzeń osobowości. Część I: farmakoterapia. Neuropsychiatria - Przegląd Kliniczny. 2013;5(2):91-96.

45. Niederhofer H. Left-handedness in a sample of nine patients with borderline personality disorder. Percept Mot Skills. 2004;99(3Pt1):849852. doi: 10.2466/pms.99.3.849-852

46.Pfeiffer E. Borderline states. Diseases of the Nervous System. 1974;35(5):212-219

47. Reitan RM. Validity of the Trail Making test as an indicator of organic brain damage. Perceptual \& Motor Skills. 1958;8:271-276. doi: 10.2466/PMS.8.7.271-276
48. Ruocco AC. The neuropsychology of borderline personality disorder: a meta-analysis and review. Psychiatry Res. 2005;137(3):191-202. doi: 10.1016/j.psychres.2005.07.004

49. Siever LJ, Weinstein LN. The neurobiology of personality disorders: implications for psychoanalysis. J Am Psychoanal Assoc. 2009;57 (2):361398. doi: $10.1177 / 0003065109333502$

50.Spitzer RL, Endicott J, Gibbon M. Crossing the border into borderline personality and borderline schizophrenia. The development of criteria. Arch Gen Psychiatry. 1979;36(1):17-24.

51.Sprock J, Rader TJ, Kendall JP, Yode CY. Neuropsychological functioning in patients with borderline personality disorder. Journal of Clinical Psychology. 2000;56(12):1587-1600.

52.Stein DJ. Borderline personality disorder: toward integration. CNS Spectr. 2009;14(7):352-356.

53.Stoffers J, Völlm BA, Rücker G, Timmer A, Huband N, Lieb K. Pharmacological interventions for borderline personality disorder. Cochrane Database Syst Rev. 2010;16(6):CD005653. doi: 10.1002/14651858. CD005653.pub2

54.Strupczewska B. Test Figury Złożonej Rey-Osterrieth’a: podręcznik. Warszawa: COMPW MEN. 1990.

55. Torgersen S, Lygren S, Oien PA, Skre I, Onstad S, Edvardsen J, et al. A twin study of personality disorders. Compr Psychiatry. 2000;41(6):416425. doi: $10.1053 /$ comp. 2000.16560

56. Torgersen $\mathrm{S}$. Genetics of patients with borderline personality disorder. Psychiatr Clin North Am. 2000;23(1):1-9.

57. Widiger TA. Issues in the validation of the personality disorders. Prog Exp Pers Psychopathol Res. 1993;16:117-136.

58. Wupperman P, Neumann CS, Whitman JB, Axelrod SR. The role of mindfulness in borderline personality disorder features. J Nerv Ment Dis. 2009;197(10):766-71. doi: 10.1097/NMD.0b013e3181b97343

59.Zanarini MC, Frankenburg FR, Yong L, Raviola G, Bradford Reich D, Hennen J, et al. Borderline psychopathology in the first-degree relatives of borderline and axis II comparison probands. J Pers Disord. 2004;18(5):439-447. doi: 10.1521/pedi.18.5.439.51327

60.Zimmerman M, Coryell W. DSM-III personality disorder diagnoses in a nonpatient sample. Demographic correlates and comorbidity. Arch Gen Psychiatry. 1989;46(8):682-689. 